\title{
Chemical Methodologies
}

journal homepage: http://chemmethod.com

Original Research article

\section{Molecular Structure, NMR, FMO, MEP and NBO Analysis of Ethyl-(Z)-3-phenyl-2-(5-phenyl-2H-1,2,3,4-tetraazol-2-yl)-2- propenoate Based on HF and DFT Calculations}

\author{
Ali Ramazania*, Masoome Sheikhib, Hooriye Yahyaeic \\ a Department of Chemistry, University of Zanjan, P. O. Box 45195-313, Zanjan, Iran \\ b Young Researchers and Elite Club, Gorgan Branch, Islamic Azad University, Gorgan, Iran \\ c Department of Chemistry, Zanjan Branch, Islamic Azad University, Zanjan, Iran.
}

\author{
ARTICLE INFORMATION \\ Received: 10 June 2017 \\ Received in revised: 25 July 2017 \\ Accepted: 10 August 2017 \\ Available online: 24 August 2017 \\ DOI: \\ 10.22631/chemm.2017.95510.1006

\section{KEYWORDS}

\section{Tetrazole} \\ DFT \\ Natural charge \\ NBO analysis \\ Electronic properties
}

\begin{abstract}
In the present work, for the first time the quantum calculations of Ethyl-(Z)-3-phenyl-2-(5-phenyl-2H-1,2,3,4-tetraazol-2-yl)-2propenoate are evaluated using the HF and B3LYP methods with $6-311++G^{* *}$ basis set. The geometry of the title compound was optimized by B3LYP/6-311++ $\mathrm{G}^{* *}$ level of theory. The theoretical ${ }^{1} \mathrm{H}$ and ${ }^{13} \mathrm{C}$ NMR chemical shift values of the title compound are calculated and compared with the experimental results. The computed data are in good agreement with the experimental data. Frontier molecular orbitals (FMOs), molecular electrostatic potential (MEP), energy gap between HOMO and LUMO, electronic properties, thermodynamic parameters, natural charges distribution (NBO charges) and NBO analysis were investigated and discussed by theoretical calculations.
\end{abstract}

Corresponding author, email: email: aliramazani@gmail.com

Department of Chemistry, University of Zanjan, P O Box 45195-313, Zanjan, Iran. 


\section{Graphical Abstract}

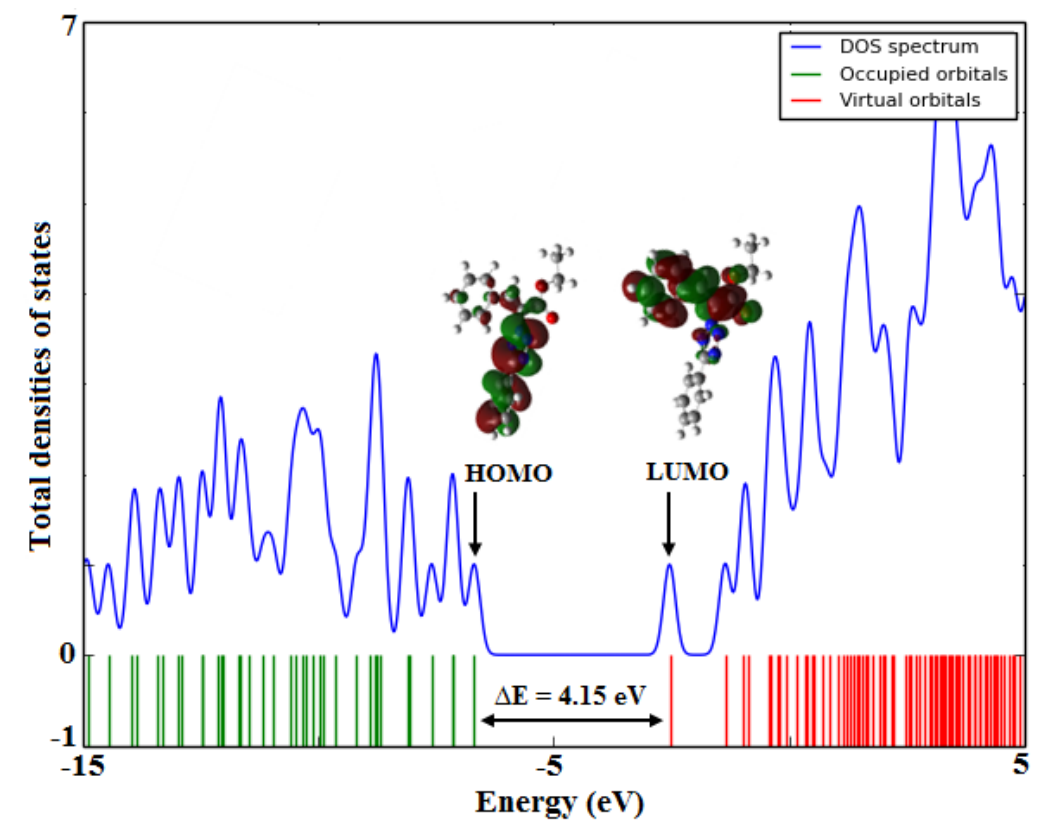

\section{Introduction}

Tetrazole derivates are compounds with the high biological activities and various procedures have been developed for their syntheses [1-4]. Tetrazole derivatives have biological activities such as fungicidal, antiviral (including HIV) antimicrobial, antiinflammatory, antilipemic, anticancer, antihypertensive and antiallergic activities [5]. Tetrazoles have applications in pharmaceuticals as lipophilic spacers and carboxylic acid surrogates, and in coordination chemistry as ligands [6].

In recent years, computational chemistry has become an important tool for chemists and a wellaccepted partner for the experimental chemistry [7-9]. Density functional theory (DFT) method has become a major tool in the methodological arsenal of computational organic chemists. In 2012, Rafie H. Abu-Eittah and coworker [10] reported a theoretical DFT study on the structural parameters and azide-tetrazole equilibrium in substituted azidothiazole systems. The results indicated electron donor substituents shift the equilibrium to the tetrazole isomer and in some cases the azide isomer cannot be isolated. Also Electron withdrawing substituents shift the equilibrium the azide isomer, in some cases, the tetrazole isomer cannot be isolated. The molecular structure, IR, NMR spectra and various other molecular properties of 7a-Aza-B-homostigmast-5eno tetrazole have been computed using B3LYP method with 6-311G(2d,p) level of theory by Mahboob Alam and coworkers [11]. They simulated the NMR spectra in gaseous and solution phase (using PCM model) by GIAO approach at same level of theory. The theoretical results are compared 
with experiments (FTIR and NMR spectra) and are found in good agreement. FMO analysis shows the charge transfer within the molecule during excitation and the HOMO and LUMO are distributed over the tetrazole. Synthesis of new compound 1-benzyl-5-amino-1H-tetrazole is reported by Ayyaz Mahmood and coworkers in 2015 [12]. They characterized the title compound using spectroscopic techniques, and its crystal structure was determined by X-ray diffraction. The monomeric, dimeric, and tetrameric structures of the title compound were determined with different DFT computational methods. The tetrameric structure calculated with the PBE1PBE/6-311G** method was found to be the best molecular model and computational level to reproduce the experimental crystal results. According to results, calculated spectroscopic properties were in good agreement with the experimental results. It was predicted that the 1-benzyl-5-amino-1H-tetrazole could present solvatochromic properties and that the HOMO-LUMO energy gap could be used as a probe for the degree of aggregation of 1-benzyl-5-amino-1H-tetrazole in different solvents.

In recent years, there has been an increasing interest in the applications of acetylenic esters in multicomponent synthesis, especially for preparing stabilized phosphorus ylides [13-16]. Recently, we have established a one-pot method for the synthesis of organophosphorus compounds [17-19]. We have reported the regioselective and stereoselective preparation of electron-poor $\mathrm{N}$-vinyl tetrazoles from the acetylenic esters and 5-benzyl-2H-tetrazole in the presence of triphenylphosphine and the structure of one of the products, namely compound ethyl-(Z)-3-phenyl-2-(5-phenyl-2H-1,2,3,4tetraazol-2-yl)-2-propenoate was confirmed by single-crystal X-ray analysis [20]. In the present work, we investigate the energetic and structural properties of crystal structures ethyl-(Z)-3phenyl-2-(5-phenyl-2H-1,2,3,4-tetraazol-2-yl)-2-propenoate [20] using the HF and DFT calculations. The optimized geometry, 1H and 13C NMR analysis, frontier molecular orbitals (FMO), detail of quantum molecular descriptors, molecular electrostatic potential (MEP), natural charge and NBO analysis of the title compound were calculated.

\section{Computational Methods}

In this work, we have carried out quantum theoretical calculations and have optimized structure of the title compound using the HF and DFT (B3LYP) [21] methods with 6-311++G** basis set by the Gaussian 09W program package [22] and calculate its properties (Fig. 1(b)). The electronic properties such as dipole moment $(\mu \mathrm{D})$, point group, EHOMO, ELUMO, HOMO-LUMO energy gap $(\Delta \mathrm{E})$ and natu-ral charges was calculated [23]. The optimized molecular structure, HOMO and LUMO surfaces were visualized using GaussView 05 program [24]. Also we calculated NMR parameters such as $1 \mathrm{H}$ and $13 \mathrm{C}$ chemical shifts [25] of the title compound using the HF/6-311++G** and B3LYP/6$311++\mathrm{G}^{* *}$ levels. The electronic structure title compound were studied by using Natural Bond 
Orbital (NBO) analysis [26] using B3LYP/6-311++G** level in order to understand hyperconjugative interactions and charge delocalization.

\section{Results and Discussion}

\section{Optimized geometry}

The optimized geometry of ethyl-(Z)-3-phenyl-2-(5-phenyl-2H-1,2,3,4-tetraazol-2-yl)-2-propenoate is performed by HF and DFT/B3LYP methods with $6-311++G^{* *}$ basis set (see Fig. 1(b)). The title compound has C1 point group symmetry. The total energy of the title compound has been calculated by HF and B3LYP methods are -1058.6721949 and -1065.2420646 Hartree, respectively (see Table 1). The selected experimental and calculated geometrical parameters of the title compound such as bond lengths $(\AA)$, bond angles $\left({ }^{\circ}\right)$ and torsion angels $\left(^{\circ}\right)$ have been obtained by HF and B3LYP methods are listed in Table 2. As can be seen in Table 2, the calculated parameters show good approximation and can be used as a foundation to calculate the other parameters for the title compound. According to Table 2, the average differences of the theoretical parameters from the experimental for bond lengths of the title compound were found to be low. We found that most of the calculated bond lengths are slightly longer than X-ray values that it is due to the fact that exper-imental result corresponds to interacting molecules in the crystal lattice, whereas computational method deals with an isolated molecule in gaseous phase [27]. From Table 2, it is found that the C1-N14 bond lengths in X-ray (1.437 $)$ and optimized structure $(1.423 \AA$ by HF and $1.428 \AA$ by B3LYP) of the title compound are shorter than the normal single C-N bond length $(1.472 \AA)$, that is due to conjugation effect of nitrogen atom with $\mathrm{C} 1=\mathrm{C} 7$ group. The $\mathrm{C}=\mathrm{O}$ bond length is shorter than $\mathrm{C}-\mathrm{C}$ bond lengths, due to strong electron-withdrawing nature of oxygen atom. The C2=03 experimental bond length of the carbonyl group $1.208 \AA$, whereas the calculated bond length by HF and B3LYP methods $1.183 \AA$ and $1.207 \AA ̊$ respectively, therefore it has typical double-bond character. The bond angel of C1-N14-N15 in the X-ray structure is $123.60^{\circ}$ and the calculated bond angel by HF and B3LYP methods is $123.5^{\circ}$ and $123.7^{\circ}$ respectively, therefore they are close to the typical hexagonal angle of $120^{\circ}$ for sp2 hybridiztion. The bond angel of C16-N17-N18 in the X-ray and by HF and B3LYP methods is $106.78^{\circ}, 106.4^{\circ}$ and $107.0^{\circ}$ respectively, which they are smaller than typical hexagonal angle of $120^{\circ}$ due to angle strain in tetrazole ring. Also they are smaller than typical angle of $108^{\circ}$ for five-membered ring due to electron-withdrawing nature of nitrogen atoms of tetrazole ring. As seen from Table 2, the bond angel of C19-C20-C21 of phenyl ring in the X-ray and by HF and B3LYP methods is $106.78^{\circ}, 106.4^{\circ}$ and $107.0^{\circ}$ respectively $120.13^{\circ}, 120.1^{\circ}$ and $120.1^{\circ}$ respectively, which they are close to the typical hexagonal angle of $120^{\circ}$. 
(a)

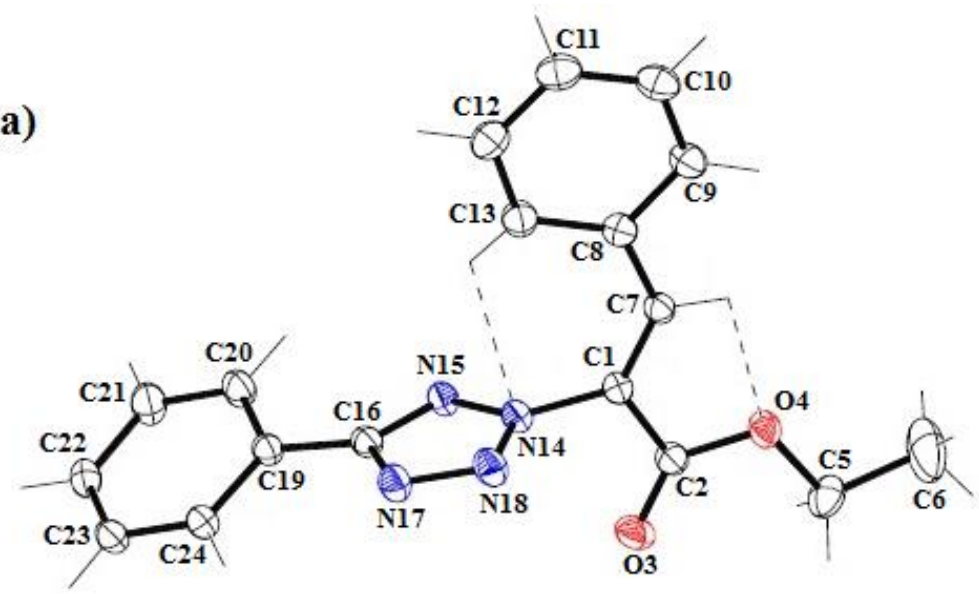

(b)
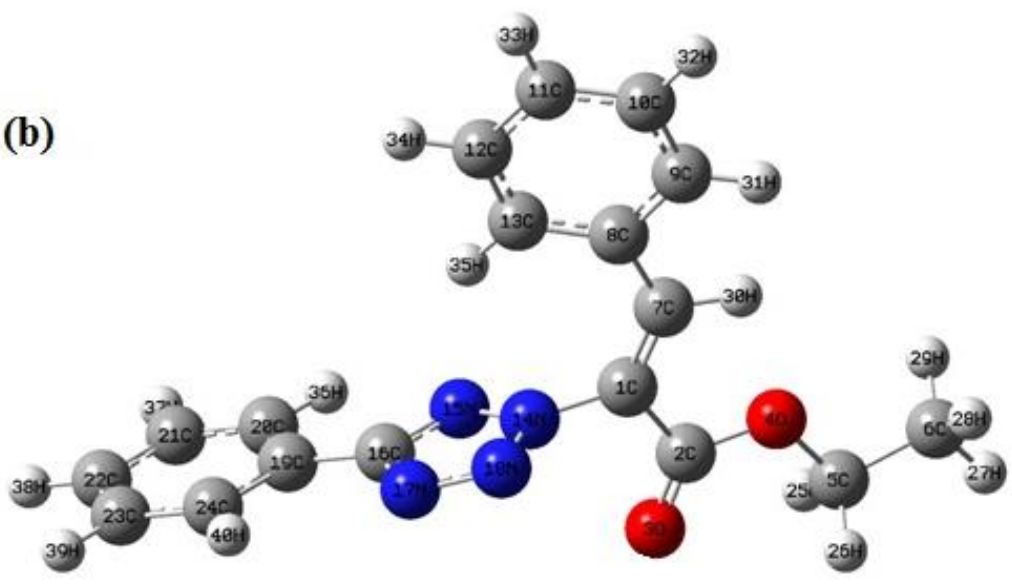

Figure 1. (a) X-Ray crystal structure of the title compound (b) The theoretical geometric structure of the title compound (optimized using the B3LYP/6-311++G** level).

Table 1. Energy (Hartree) and point group of the title compound calculated by HF and B3LYP methods with $6-311++G^{* *}$ basis set.

\begin{tabular}{|l|l|l|}
\hline Level & Energy (Hartree) & point group \\
\hline $\mathrm{HF} / 6-311++\mathrm{G}^{* *}$ & -1058.6721949 & $\mathrm{C} 1$ \\
\hline $\mathrm{B} 3 \mathrm{LYP} / 6-311++\mathrm{G}^{* *}$ & -1065.2420646 & $\mathrm{C} 1$ \\
\hline
\end{tabular}

Table 1. Energy (Hartree) and point group of the title compound calculated by HF and B3LYP methods with 6-311++G** basis set.

\begin{tabular}{|c|c|c|c|}
\hline Parameter & Experimentala $^{\mathbf{a}}$ & $\mathrm{HF} / 6-311++\mathrm{G}^{* *}$ & B3LYP/6-311++G** \\
\hline \multicolumn{4}{|l|}{ Bond lengths( $(\AA)$} \\
\hline $\mathrm{C} 1-\mathrm{C} 2$ & $1.492(2)$ & 1.492 & 1.491 \\
\hline C2-03 & $1.208(13)$ & 1.183 & 1.207 \\
\hline $\mathrm{C} 2-04$ & $1.337(13)$ & 1.318 & 1.348 \\
\hline O4-C5 & $1.458(13)$ & 1.428 & 1.452 \\
\hline $\mathrm{C} 1-\mathrm{C} 7$ & $1.337(15)$ & 1.327 & 1.346 \\
\hline C7-C8 & $1.463(15)$ & 1.474 & 1.461 \\
\hline
\end{tabular}




\begin{tabular}{|c|c|c|c|}
\hline C8-C9 & $1.404(16)$ & 1.394 & 1.407 \\
\hline C9-C10 & $1.391(16)$ & 1.383 & 1.390 \\
\hline C10-C11 & $1.389(17)$ & 1.384 & 1.394 \\
\hline $\mathrm{C} 11-\mathrm{C} 12$ & $1.392(18)$ & 1.387 & 1.396 \\
\hline C13-C8 & $1.405(15)$ & 1.394 & 1.407 \\
\hline C1-N14 & $1.437(13)$ & 1.423 & 1.428 \\
\hline N14-N15 & $1.333(13)$ & 1.313 & 1.331 \\
\hline N15-C16 & $1.338(13)$ & 1.300 & 1.331 \\
\hline C16-N17 & $1.361(13)$ & 1.351 & 1.365 \\
\hline N17-N18 & $1.318(13)$ & 1.269 & 1.299 \\
\hline N18-N14 & $1.336(12)$ & 1.291 & 1.336 \\
\hline C16-C19 & $1.464(15)$ & 1.474 & 1.466 \\
\hline C19-C20 & $1.400(15)$ & 1.390 & 1.401 \\
\hline $\mathrm{C} 20-\mathrm{C} 21$ & $1.388(17)$ & 1.383 & 1.391 \\
\hline C21-C22 & $1.394(16)$ & 1.387 & 1.395 \\
\hline $\mathrm{C} 22-\mathrm{C} 23$ & $1.390(15)$ & 1.385 & 1.394 \\
\hline C23-C24 & $1.390(16)$ & 1.385 & 1.392 \\
\hline \multicolumn{4}{|l|}{ Bond angles $\left({ }^{\circ}\right)$} \\
\hline $\mathrm{C} 1-\mathrm{C} 2-\mathrm{O} 3$ & 123.41(9) & 122.8 & 123.5 \\
\hline C1-C2-04 & $111.63(9)$ & 113.0 & 112.3 \\
\hline O3-C2-04 & $124.96(10)$ & 124.2 & 124.2 \\
\hline $\mathrm{C} 2-04-\mathrm{C} 5$ & $116.15(9)$ & 117.5 & 116.1 \\
\hline C1-C7-C8 & 132.01(9) & 131.1 & 131.5 \\
\hline C7-C8-C9 & $116.15(9)$ & 116.8 & 117.0 \\
\hline C8-C9-C10 & $120.95(10)$ & 121.0 & 121.2 \\
\hline C1-N14-N15 & $123.60(8)$ & 123.5 & 123.7 \\
\hline N14-N15-C16 & $101.62(8)$ & 102.4 & 102.0 \\
\hline N15-C16-N17 & $111.86(9)$ & 110.9 & 111.4 \\
\hline C16-N17-N18 & $106.78(8)$ & 106.4 & 107.0 \\
\hline N17-N18-N14 & $105.59(8)$ & 107.3 & 106.1 \\
\hline N15-C16-C19 & 123.48(9) & 125.1 & 124.6 \\
\hline C16-C19-C20 & $120.84(9)$ & 120.4 & 120.6 \\
\hline C19-C20-C21 & $120.13(10)$ & 120.1 & 120.1 \\
\hline C20-C21-C22 & $120.15(10)$ & 120.2 & 120.3 \\
\hline $\mathrm{C} 21-\mathrm{C} 22-\mathrm{C} 23$ & $120.10(10)$ & 119.8 & 119.8 \\
\hline C22-C23-C24 & $120.02(10)$ & 120.2 & 120.3 \\
\hline \multicolumn{4}{|l|}{ Torsion angels $\left({ }^{\circ}\right)$} \\
\hline C1-C2-04-C5 & $174.54(8)$ & -179.9 & 179.2 \\
\hline O3-C2-04-C5 & $-4.04(15)$ & -0.10 & -0.7 \\
\hline C1-C7-C8-C9 & $175.02(10)$ & -157.4 & 164.8 \\
\hline C7-C8-C9-C10 & $178.78(9)$ & 179.5 & -179.8 \\
\hline C8-C9-C10-C11 & $-0.36(17)$ & 1.10 & -0.90 \\
\hline C1-N14-N15-C16 & 177.01(9) & 177.1 & 176.9 \\
\hline N15-C16-N17-N18 & $-0.53(12)$ & -0.30 & -0.30 \\
\hline C16-N17-N18-N14 & $0.80(11)$ & 0.70 & 0.50 \\
\hline N15-C16-C19-C20 & $-18.01(16)$ & -1.80 & 2.80 \\
\hline
\end{tabular}




\begin{tabular}{|c|c|c|c|}
\hline $\mathrm{C} 16-\mathrm{C} 19-\mathrm{C} 20-\mathrm{C} 21$ & $173.15(10)$ & 179.9 & -179.0 \\
\hline $\mathrm{C} 19-\mathrm{C} 20-\mathrm{C} 21-\mathrm{C} 22$ & $0.71(18)$ & 0.03 & -0.04 \\
\hline $\mathrm{C} 20-\mathrm{C} 21-\mathrm{C} 22-\mathrm{C} 23$ & $1.60(18)$ & -0.03 & -0.07 \\
\hline $\mathrm{C} 21-\mathrm{C} 22-\mathrm{C} 23-\mathrm{C} 24$ & $-2.16(17)$ & 0.02 & 0.09 \\
\hline
\end{tabular}

a Taken from Ref. [20].

In addition, the hydrogen bonds length values of experimental [20] and theoretical of the title compound summarized in Table 3. X-ray diffraction analysis of the studied compound shows that the structure is stabilized by intramolecular hydrogen bond. According to experimental results is obtained [20], it revealed that the title molecule has two intramolecular hydrogen bonds (see Fig. 1 (a)). By knowing the bond length, the strength of the hydrogen bond can be determined as very

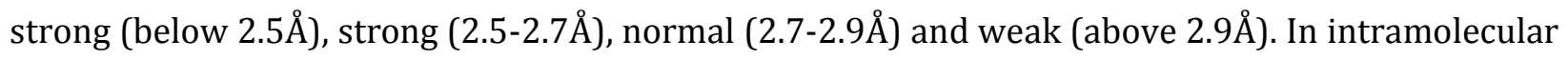
C7-H30 ...04 hydrogen bond, the experimental value of bond length H30...04 are 2.36 calculated values by HF and B3LYP methods are $2.30 \AA$ and $2.31 \AA$ respectively, that suggesting the existence of very strong intramolecular hydrogen bond. In the other intramolecular hydrogen bond [C17-H35...N14] of the title compound the experimental value of bond length H35...N14 are 2.49A, while the calculated values by HF and B3LYP methods are $2.51 \AA$ and $2.45 \AA ̊$ respectively. These values suggest the existence of very strong intramolecular hydrogen bond.

Table 3. N12-H26...08 hydrogen-bond geometry ( $\AA$ ) of the title compound (Experimental and calculated by HF and B3LYP methods with 6-311++G** basis set.)

\begin{tabular}{|c|c|c|c|c|c|c|c|c|c|}
\hline \multirow[b]{2}{*}{ D-H...A } & \multicolumn{2}{|c|}{ D-H (Å) } & \multirow[b]{2}{*}{ B3LYP } & \multicolumn{2}{|c|}{ H...A(А̊) } & \multirow[b]{2}{*}{ B3LYP } & \multicolumn{2}{|c|}{ D...A(Å) } & \multirow[b]{2}{*}{ B3LYP } \\
\hline & Exp.a & HF & & Exp.a & HF & & Exp.a & HF & \\
\hline $\begin{array}{l}\text { C7- } \\
\text { H30...04 }\end{array}$ & $0.96(2)$ & 1.07 & 1.08 & $2.36(2)$ & 2.30 & 2.31 & $2.730(3)$ & 2.735 & 2.755 \\
\hline $\begin{array}{l}\text { C17- } \\
\text { H35...N14 }\end{array}$ & $0.94(2)$ & 1.07 & 1.08 & $2.49(2)$ & 2.51 & 2.45 & $3.072(3)$ & 3.092 & 3.079 \\
\hline
\end{tabular}

a Taken from Ref. [20].

\section{NMR chemical shift analysis}

In the present study, the theoretical $1 \mathrm{H}$ and $13 \mathrm{C}$ NMR chemical shift values of the title compound were calculated by HF and B3LYP methods with $6-311++G^{* *}$ basis set using GIAO method. Then calculated $1 \mathrm{H}$ and 13C NMR chemical shifts compared with the experimental values (see Table 4). $1 \mathrm{H}$ and $13 \mathrm{C}$ NMR chemical shifts are reported in ppm relative to TMS. According to results, it can be seen a good agreement between experimental and calculated values. The difference between the theoretical and experimental values may be due to the fact that theoretical calculations of the title compound have been done in gas phase. The hydrogen atoms of $\mathrm{CH} 3$ group appear at lower delta values rather than hydrogen atoms of $\mathrm{CH} 2$ group due to shielding effect in $\mathrm{CH} 3$ group and 
attachment of $\mathrm{CH} 2$ group to $\mathrm{O} 4$ atom of ester group. The hydrogen atoms of $\mathrm{CH} 2$ group appeared in recorded $1 \mathrm{H}$ NMR at $4.33 \mathrm{ppm}$, while the theoretical values by HF and DFT/B3LYP methods appeared at $4.12 \mathrm{ppm}$ and $4.20 \mathrm{ppm}$, respectively. The CH3 protons appeared at $1.29 \mathrm{ppm}$ in experimental 1H NMR spectrum while calculated chemical shift values for CH3 protons appeared at $1.45 \mathrm{ppm}$ and $1.23 \mathrm{ppm}$ by HF and DFT/B3LYP methods, respectively. The aromatic protons in recorded $1 \mathrm{H}$ NMR appeared at the range of 6.88-8.27 ppm, whereas the theoretical values by HF and B3LYP methods appeared at 6.89-9.41 ppm and 6.31-8.89 ppm, respectively. From experimental 13C NMR spectrum it is found that, $\mathrm{C}$ atom in $\mathrm{CH} 2$ group has the high chemical shift value (62.56 ppm) compared with carbon atoms atom in CH3 group (14.10 ppm), due to the presence of electro-negative oxygen atom 04. The carbon atom of carbonyl group has peak at 165.6 ppm in experi-mental 13C NMR spectra of title compound, which matches well with the calculated chemical shift at 169.09 and 168.07 ppm by HF and B3LYP methods respectively. Also we investigated the relation between experimental and theoretical chemical shift values by comparing the experimental and calculated results and obtained linear function formula for Fig. 2. According to results, the experi-mental values are in good agreement with the theoretical values by B3LYP/6$311++G^{* *}$ level com-pared with HF/6-311++G** level.

Table 4. The selected theoretical and experimental $1 \mathrm{H}$ and $13 \mathrm{C}$ isotropic chemical shifts for the title compound.

\begin{tabular}{|c|c|c|c|}
\hline \multirow[t]{2}{*}{ Assignment } & \multirow{2}{*}{$\begin{array}{l}\text { Experimental a } \\
\text { (CDCl3) }\end{array}$} & \multicolumn{2}{|c|}{ Theoretical } \\
\hline & & $\begin{array}{l}\mathrm{HF} / 6- \\
311++\mathrm{G}^{* *}\end{array}$ & $\begin{array}{l}\text { B3LYP/6- } \\
311++G^{* *}\end{array}$ \\
\hline \multicolumn{4}{|l|}{1 H NMR } \\
\hline $3 \mathrm{H}, \mathrm{CH} 3$ & 1.29 & 1.45 & 1.23 \\
\hline $2 \mathrm{H}, \mathrm{CH} 2$ & 4.33 & 4.12 & 4.20 \\
\hline $1 \mathrm{H}, \mathrm{C}=\mathrm{CH}$ & 8.17 & 8.80 & 8.27 \\
\hline $10 \mathrm{H}$, aromatic & $6.88-8.27$ & $6.89-9.41$ & $6.31-8.89$ \\
\hline \multicolumn{4}{|l|}{ 13C NMR } \\
\hline $1 \mathrm{C}, \mathrm{CH} 3$ & 14.10 & 20.25 & 14.20 \\
\hline 1C, $\mathrm{CH} 2$ & 62.56 & 61.75 & 65.25 \\
\hline $8 \mathrm{CH}$ & $127.15-131.81$ & $138.03-158.71$ & $132.03-149.21$ \\
\hline \multirow[t]{4}{*}{$4 \mathrm{C}$} & 125.58 & 133.75 & 132.63 \\
\hline & 126.96 & 138.83 & 134.08 \\
\hline & 142.18 & 139.73 & 136.84 \\
\hline & 162.29 & 172.70 & 171.98 \\
\hline CO of ester & 165.6 & 169.09 & 168.07 \\
\hline
\end{tabular}

a Taken from Ref. [20]. 


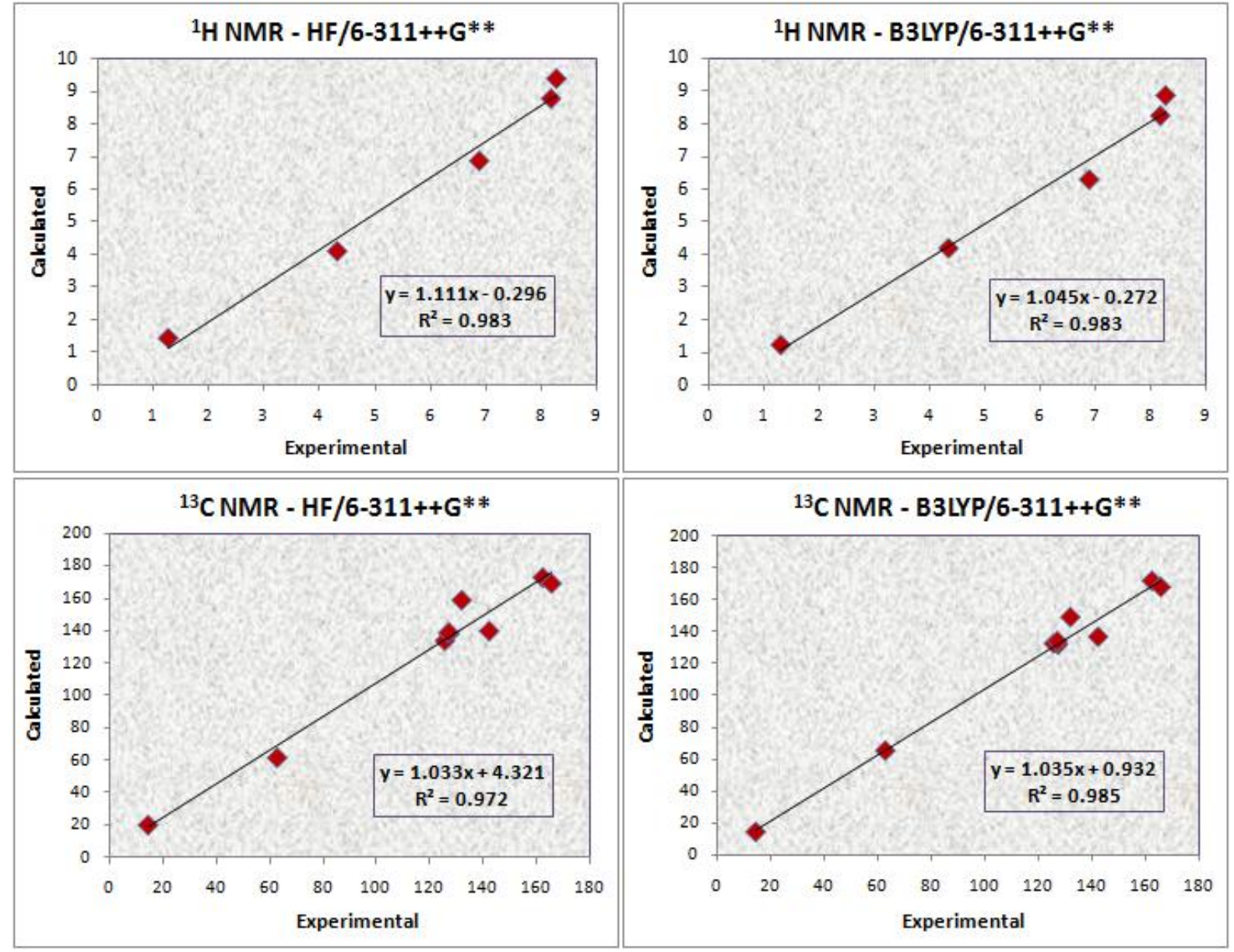

Figure 2. Correlation graphics of theoretical chemical shift values of $1 \mathrm{H}$ and $13 \mathrm{C}$ NMR of the title compound.

\section{Natural charge analysis}

The atomic charges play an important role on molecular polarizability, dipole moment, electronic structure and lot of related properties of molecular systems. The charge distributions over the atoms suggest the formation of donor and acceptor pairs involving the charge transferring the molecule. We calculated the charge distributions for equilibrium geometry of the title compound by the NBO (natural charge) charges [28] using the HF/6-311++G** and B3LYP/6-311++G** levels. The calculated natural charges are listed in Table 5 (Atoms labeling is according to Fig. 1). The total charge of the investigated compound is equal to zero. Also Fig. 3 shows results of natural charges in graphical form. The natural charge (NBO) analysis of the title compound shows that carbon atoms have both positive and negative charges magnitudes. According to results, the highest positive charge is observed for C2 atom (0.93837e by HF method and 0.78138 e by B3LYP method) of carbonyl group due to attachment to 03 and 04 atoms and their electron-withdrawing nature, therefore it is more acidic. The $\mathrm{C} 6$ ( $\mathrm{CH} 3$ group) atom has the highest negative charge compared with 
other carbon atoms $(0.51459 \mathrm{e}$ by $\mathrm{HF}$ method and $0.59097 \mathrm{e}$ by B3LYP method) due to hyperconjugation effect. All carbon atoms of phenyl rings have negative charge. According to Natural charge's plot is shown in Fig. 3, all hydrogen atoms have the positive charge and H30 atom has the highest positive charge $(0.21455 \mathrm{e}$ by HF method and $0.23040 \mathrm{e}$ by B3LYP method) compared with other hydrogen atoms due to participate in forming strong intramolecular hydrogen bonding (C7-H30...04).

Table 5. Natural Charges (NBO charges, e) of the title compound calculated using the B3LYP/6-311++G** and $\mathrm{HF} / 6-311++\mathrm{G}^{* *}$ levels.

\begin{tabular}{|l|l|l|l|l|l|l|l|l|}
\hline \multicolumn{3}{|c|}{ HF/6-311++G** } & & \multicolumn{4}{c|}{ B3LYP/6-311++G** } \\
\hline Atom & $\begin{array}{l}\text { Natural } \\
\text { charge }\end{array}$ & Atom & $\begin{array}{l}\text { Natural } \\
\text { charge }\end{array}$ & & Atom & $\begin{array}{l}\text { Natural } \\
\text { charge }\end{array}$ & Atom & $\begin{array}{l}\text { Natural } \\
\text { charge }\end{array}$ \\
\hline C1 & 0.01383 & C21 & -0.19000 & & C1 & 0.04491 & C21 & -0.19947 \\
\hline C2 & 0.93837 & C22 & -0.17634 & & C2 & 0.78138 & C22 & -0.19321 \\
\hline O3 & -0.66256 & C23 & -0.19684 & & O3 & -0.57567 & C23 & -0.20622 \\
\hline O4 & -0.65529 & C24 & -0.13756 & & O4 & -0.57221 & C24 & -0.15374 \\
\hline C5 & 0.06077 & H25 & 0.15675 & & C5 & -0.03038 & H25 & 0.18661 \\
\hline C6 & -0.51459 & H26 & 0.15797 & & C6 & -0.59097 & H26 & 0.18581 \\
\hline C7 & -0.01001 & H27 & 0.18172 & & C7 & -0.07547 & H27 & 0.20984 \\
\hline C8 & -0.12180 & H28 & 0.17964 & & C8 & -0.10370 & H28 & 0.20426 \\
\hline C9 & -0.14159 & H29 & 0.17803 & & C9 & -0.15631 & H29 & 0.20531 \\
\hline C10 & -0.19626 & H30 & 0.21455 & & C10 & -0.20332 & H30 & 0.23040 \\
\hline C11 & -0.15662 & H31 & 0.19029 & & C11 & -0.17385 & H31 & 0.20470 \\
\hline C12 & -0.18789 & H32 & 0.19561 & & C12 & -0.19416 & H32 & 0.20984 \\
\hline C13 & -0.13826 & H33 & 0.19414 & & C13 & -0.15398 & H33 & 0.20852 \\
\hline N14 & -0.06842 & H34 & 0.19742 & & N14 & -0.04548 & H34 & 0.21145 \\
\hline N15 & -0.29051 & H35 & 0.20486 & & N15 & -0.26134 & H35 & 0.21539 \\
\hline C16 & 0.35469 & H36 & 0.20695 & & C16 & 0.30709 & H36 & 0.22048 \\
\hline N17 & -0.32162 & H37 & 0.19146 & & N17 & -0.27403 & H37 & 0.20580 \\
\hline N18 & 0.01942 & H38 & 0.19042 & & N18 & -0.02703 & H38 & 0.20472 \\
\hline C19 & -0.11252 & H39 & 0.19198 & & C19 & -0.10800 & H39 & 0.20624 \\
\hline C20 & -0.15080 & H40 & 0.21062 & & C20 & -0.16863 & H40 & 0.22445 \\
\hline
\end{tabular}

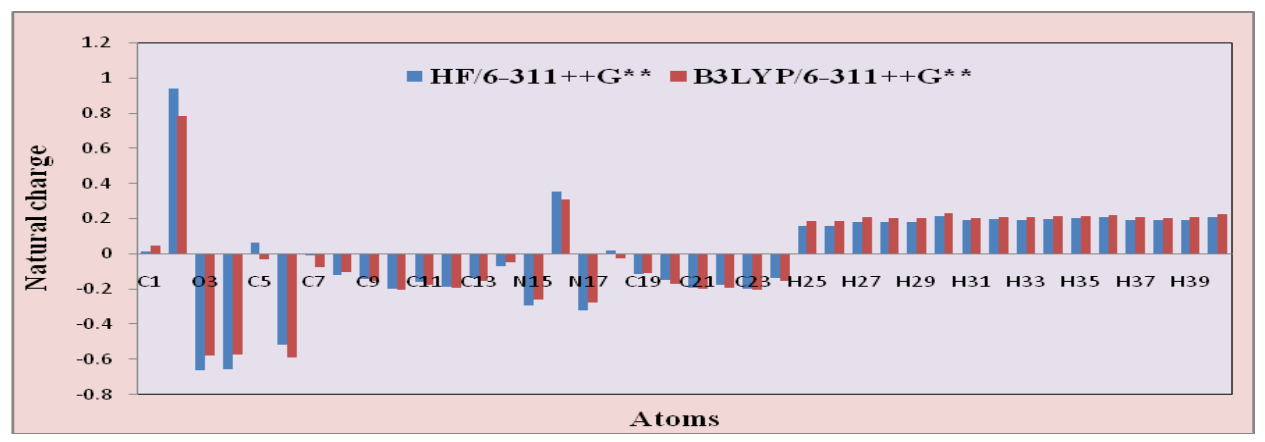

Figure 3. Natural charges distribution of the title compound calculated using the HF/6-311++G** and B3LYP/6-311++G** levels. 


\section{Thermodynamic properties}

The total energy of a molecule is the sum of translational, rotational, vibrational and electronic energies. The statistical thermochemical analysis of the title compound is carried out considering the molecule to be at room temperature of $25^{\circ} \mathrm{C}$ and 1 atmospheric pressure [29]. The thermodynamic parameters, such as zero point vibrational energy, rotational constant, heat capacity (C) and the entropy (S) of the title compound by HF and B3LYP methods with 6-311++G** basis set are listed in Table 6.

Table 6. The calculated thermodynamic parameters at $25 \mathrm{oC}$ and $1 \mathrm{~atm}$ pressure for the title compound.

\begin{tabular}{|l|l|l|}
\hline Property Thermodynamic parameters & HF/6-311++G* & B3LYP/6-311++G* \\
\hline Zero-point correction (Hartree/Particle) & 0.335192 & 0.312185 \\
\hline Thermal correction to Energy & 0.354610 & 0.332864 \\
\hline Thermal correction to Enthalpy & 0.355555 & 0.333808 \\
\hline Thermal correction to Gibbs Free Energy & 0.282433 & 0.258388 \\
\hline Sum of electronic and zero-point Energies & -1058.337002 & -1064.929879 \\
\hline Sum of electronic and thermal Energies & -1058.317585 & -1064.909201 \\
\hline Sum of electronic and thermal Enthalpies & -1058.316640 & -1064.908256 \\
\hline Sum of electronic and thermal Free Energies & -1058.389762 & -1064.983677 \\
\hline E (Thermal) (KCal/Mol) & 222.521 & 208.875 \\
\hline CV (Cal/Mol-Kelvin) & 71.667 & 77.506 \\
\hline S (Cal/Mol-Kelvin) & 153.898 & 158.735 \\
\hline
\end{tabular}

\section{Electronic properties}

Quantum chemical methods are important for obtaining information about molecular structure and electrochemical behavior. A Frontier Molecular Orbitals (FMO) analysis [26, 30] was done for the title compound using the B3LYP/6-311++G** level. The energies of two important molecular orbitals of the title compound in gas phase such as EHOMO, ELUMO and the HOMO-LUMO energy gap $(\Delta \mathrm{E})$ of the title compound were calculated as shown in the Table 7 and Fig. 4 . The values of energy of the highest occupied molecular orbital (EHOMO) can act as an electron donor and the lowest unoccupied molecular orbital (ELUMO) can act as the electron acceptor [31]. The energy of HOMO $(-6.69 \mathrm{eV})$ is directly related to the ionization potential, while the energy of LUMO $(-2.54 \mathrm{eV})$ is related to the electron affinity. The title compound contains 84 occupied molecular orbital and 551 unoccupied virtual molecular orbital. As shown in Fig. 4, the positive and negative phase is represented in green and red color respectively. The graphic pictures of orbitals in Fig. 4 show HOMO orbital of molecule is localized mainly on on one of phenyl rings and tetrazole ring, whereas LUMO orbital of molecule is localized mainly on one of phenyl rings, $\mathrm{C}=\mathrm{O}$ function and $\mathrm{C}=\mathrm{C}$ bond. The HOMO-LUMO energy gap $(\Delta \mathrm{E})$ explains the eventual charge transfer interaction taking within the molecule. As seen in Table 8, the HOMO-LUMO energy gap $(\Delta \mathrm{E})$ of the title compound is $4.15 \mathrm{eV}$ 
that reflect the chemical activity of the molecule. The calculated energy gap clearly is shown in DOS plot (see Fig. 5) [30].

A detail of quantum molecular descriptors of the title compound such as ionization potential ( $\mathrm{I}=-$ EHOMO), electron affinity ( $A=-$ ELUMO), global hardness $(\eta=I-A / 2)$, electronegativity $(\chi=I+A / 2)$, elec-tronic chemical potential $(\mu=-(I+A) / 2)$ and electrophilicity $(\omega=\mu 2 / 2 \eta)$, chemical softness $(S=1 / \eta)[26]$ are calculated and are listed in Table 7. The global hardness ( $\eta$ ) corresponds to the HOMO-LUMO energy gap. A molecule with a small energy gap has high chemical reactivity, low kinetic sta-bility and is a soft molecule, while a hard molecule has a large energy gap [32]. The ionization po-tential value $(6.69 \mathrm{eV})$ obtained by DFT method also support the stability of the title molecule. Elec-tronegativity $(\chi)$ is a measure of the power of an atom or a group of atoms to attract electrons [26] and the chemical softness (S) describes the capacity of an atom or a group of atoms to receive elec-trons [26]. Dipole moment $(\mu \mathrm{D})$ is a good measure for the asymmetric nature of a structure. The size of the dipole moment depends on the composition and dimensionality of the 3D structures. The calculated dipole moment value shows that the molecule is highly polarity in nature. As shown in Table 7, dipole moment and point group of the title compound is 4.7194 Debye.

Table 7. Electronic properties of the title compound calculated by B3LYP method with $6-311++G^{* *}$ basis sets.

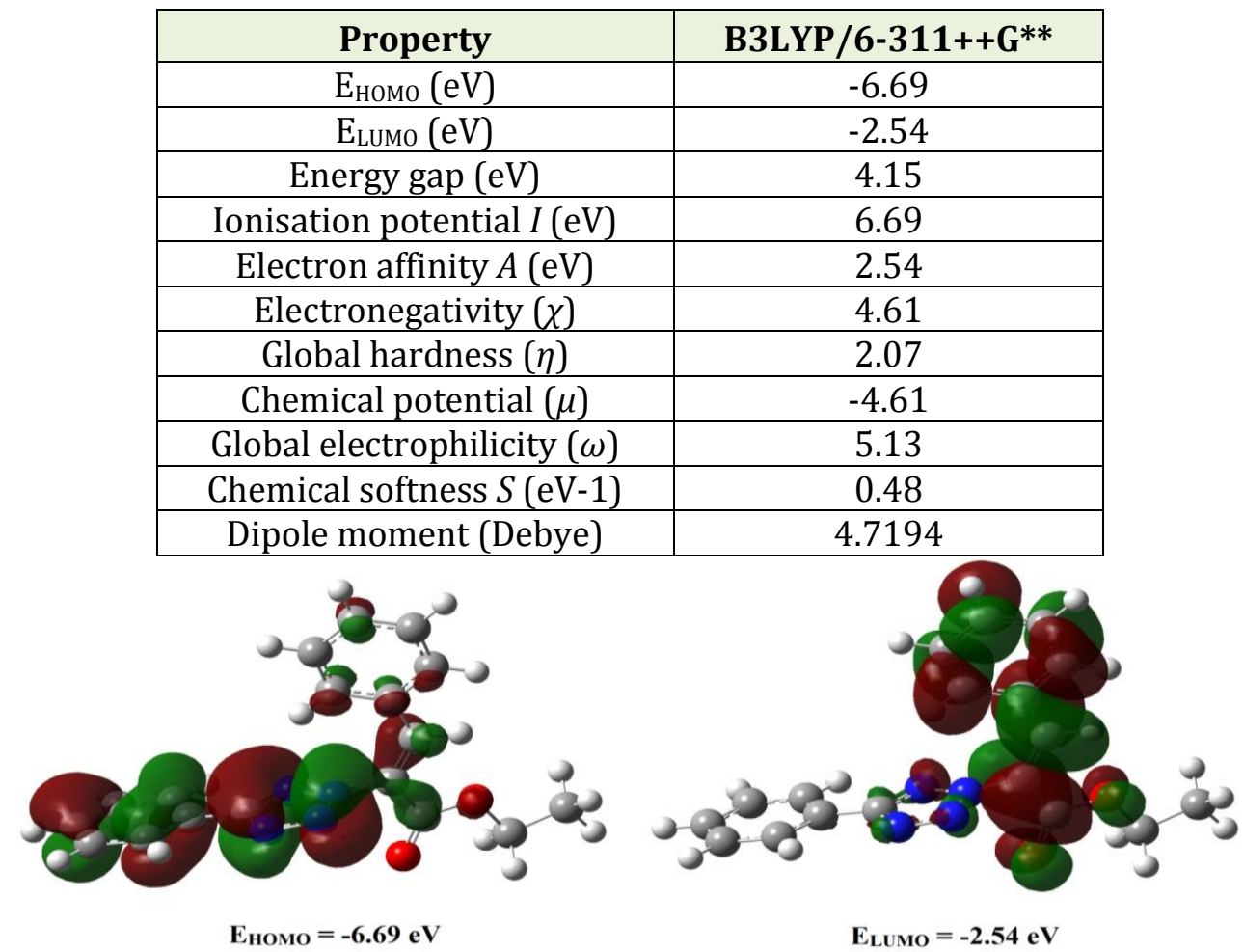

Figure 4. Calculated Frontier molecular orbitals of the title compound (using the B3LYP/6-311++G**). 


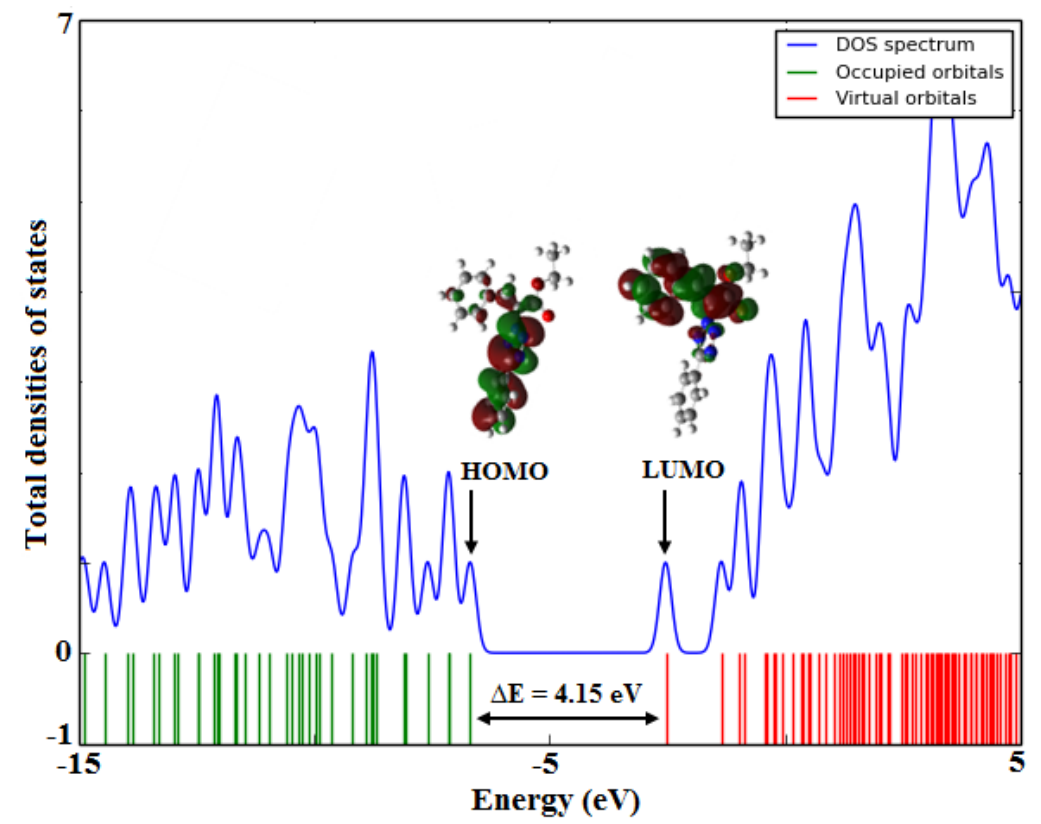

Figure 5. Calculated DOS plots of the title compound (using the B3LYP/6-311++G**).

\section{Molecular electrostatic potential (MEP)}

The molecular electrostatic potential (MEP) [30,33] was checked out by theoretical calculations using B3LYP/6-311++G** level. Molecular electrostatic potential shows the electronic density and is useful in recognition sites for electrophilic attack and nucleophilic reactions as well as hydrogen bonding interactions. The different values of the electrostatic potential at the surface are represented by different colors. The negative areas (red, orange and yellow color) of MEP were related to electrophilic reactivity, the positive areas (blue color) ones to nucleophilic reactivity and green color is neutral regions. According to the MEP map in Fig. 6, negative region of compound is mainly focused on phenyl ring and 03 atom of carbonyl group with the highest red color intensity which is caused by the contribution of lone-pair electrons of oxygen atom, therefore they are suitable site for electrophilic attack. Also tetrazole ring with yellow color is negative region. The positive potential sites (blue color) are around the hydrogen atoms.

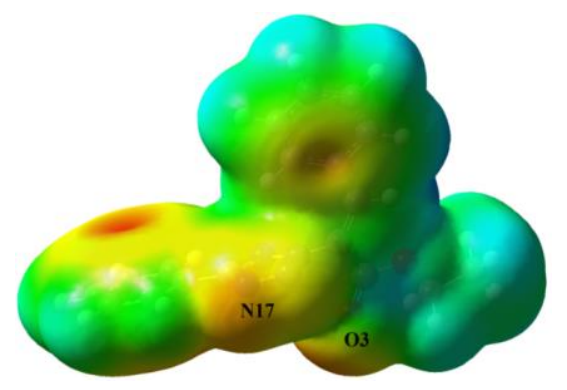

Figure 6. Molecular electrostatic potential (MEP) map of the title compound calculated using the B3LYP/6$311++\mathrm{G}^{* *}$ level. 


\section{NBO analysis}

Natural bond orbital (NBO) analysis is important method for studying intra- and inter-molecular bonding and interaction between bonds [34]. Electron donor orbital, acceptor orbital and the interacting stabilization energy resulting from the second-order micro disturbance theory are reported in Table 8. The electron delocalization from filled NBOs (donors) to the empty NBOs (acceptors) describes a conjugative electron transfer process between them. For each donor (i) and acceptor (j), the stabilization energy $\mathrm{E}(2)$ associated with the delocalization $\mathrm{i} \rightarrow \mathrm{j}$ is estimated [35]:

$E^{(2)}=\Delta E_{i j}=q_{i} \frac{F(i, j)^{2}}{\varepsilon_{j}-\varepsilon_{i}}$

where qi is the donor orbital occupancy, $\varepsilon j$ and $\varepsilon i$ are diagonal elements and $F(i, j)$ is the off diagonal NBO Fock matrix element. The resonance energy (E(2)) detected the quantity of participation of electrons in the resonance between atoms. The larger $E(2)$ value, the more intensive is the interaction between electron donors and acceptor, i.e. the more donation tendency from electron donors to electron acceptors and the greater the extent of conjugation of the whole system [34]. Delocalization of electron density between occupied Lewis-type (bond or lone pair) NBO orbitals and formally unoccupied (antibond or Rydgberg) non Lewis NBO orbitals correspond to a stabilization donor-acceptor interaction. NBO analysis has been performed for title compound at the B3LYP/6-311++G** level in order to elucidate the intramolecular, rehybridization and delocalization of elec-tron density within the molecule. The strong, moderate and weak intramolecular hyperconjugative interactions of the title compound such as $\pi \rightarrow \pi^{*}, \pi^{*} \rightarrow \pi^{*}, \sigma \rightarrow \sigma^{*}$, $n \rightarrow \sigma^{*}$ and $n \rightarrow \sigma^{*}$ transitions are pre-sented in Table 8. As shown in Table 8, the resonance energies of $\pi \rightarrow \pi^{*}$ transitions are higher than $\sigma \rightarrow \sigma^{*}$ transitions. The intramolecular hyperconjugative interactions of the $\pi \rightarrow \pi^{*}$ transitions that lead to a strong delocalization are such as C10-C11 $\rightarrow$ C8-C9, $\mathrm{C} 12-\mathrm{C} 13 \rightarrow \mathrm{C} 10-\mathrm{C} 11, \mathrm{~N} 17-\mathrm{N} 18 \rightarrow \mathrm{N} 15-\mathrm{C} 16$ and C19-C24 $\rightarrow$ N15-C16 with resonance energies (E(2)) 22.31, 21.15, 24.07 and $23.17 \mathrm{kcal} / \mathrm{mol}$, respectively. According to NBO analysis, the $\pi(\mathrm{C} 1-\mathrm{C} 7)$ orbital participates as donor and the anti-bonding $\pi^{*}(\mathrm{C} 2-03)$ and $\pi^{*}(\mathrm{C} 8-\mathrm{C} 9)$ orbitals act as acceptor with resonance energies (E(2)) of is 19.12 and $8.75 \mathrm{kcal} / \mathrm{mol}$, respectively. These values indicate the large charge transfer from the $\pi(\mathrm{C} 1-\mathrm{C} 7)$ to $\pi^{*}(\mathrm{C} 2-03)\left[\pi(\mathrm{C} 1-\mathrm{C} 7) \rightarrow \pi^{*}(\mathrm{C} 2-03)\right]$ compare with $\pi(\mathrm{C} 1-\mathrm{C} 7) \rightarrow \pi^{*}(\mathrm{C} 8-\mathrm{C} 9)$. According to NBO analysis, the important intramolecular hyperconjugative interactions of the $\sigma \rightarrow \sigma^{*}$ including C7-H30 $\rightarrow \mathrm{C} 1-\mathrm{N} 14, \mathrm{C} 19-\mathrm{C} 24 \rightarrow \mathrm{C} 23-\mathrm{H} 39$ and C19-C24 $\rightarrow \mathrm{C} 24-\mathrm{H} 40$ transitions show the stabilization energies of 9.74, 9.68 and $20.70 \mathrm{kcal} / \mathrm{mol}$, respectively. The $\pi^{*} \rightarrow \pi^{*}$ transitions have the highest res-onance energies compared with other interactions of the 
AliRamazani et al.

title compound such as C2-O3 $\rightarrow$ C1-C7, N15-C16 $\rightarrow$ C19-C24 and N17-N18 $\rightarrow$ N15-C16 with resonance energies (E(2)) 67.78, 52.47 and $67.36 \mathrm{kcal} / \mathrm{mol}$ respectively, that lead to stability of the title compound. According to the $n \rightarrow \sigma^{*}$ and $n \rightarrow \pi^{*}$ interactions, the strongest interactions are due to $\mathrm{n} 2(\mathrm{O} 3) \rightarrow \sigma^{*}(\mathrm{~N} 12-\mathrm{H} 26), \quad \mathrm{n} 2(\mathrm{O} 4) \rightarrow \pi^{*}(\mathrm{C} 2-\mathrm{O} 3)$ and $\mathrm{n} 1(\mathrm{~N} 14) \rightarrow \pi^{*}(\mathrm{~N} 17-\mathrm{N} 18)$ with stabilization energies of $31.80,45.32$ and $48.54 \mathrm{kcal} / \mathrm{mol}$, respective-ly.

Table 8. Significant donor-acceptor interactions and second order perturbation energies of the title compound calculated using the B3LYP/6-311++G** level.

\begin{tabular}{|c|c|c|c|c|c|c|}
\hline Donor (i) & Occupancy & Acceptor (j) & Occupancy & $\begin{array}{l}\mathrm{E}(2)^{\mathrm{a}} \\
\mathrm{kcal} / \mathrm{mol}\end{array}$ & $\begin{array}{l}E(j)-E(i) b \\
\text { a.u. }\end{array}$ & $\begin{array}{l}F(i, j)^{c} \\
\text { a.u. }\end{array}$ \\
\hline \multirow[t]{2}{*}{$\pi(\mathrm{C} 1-\mathrm{C} 7)$} & 1.85887 & $\pi^{*}(\mathrm{C} 2-03)$ & 0.25711 & 19.12 & 0.31 & 0.070 \\
\hline & & $\pi^{*}(\mathrm{C} 8-\mathrm{C} 9)$ & 0.38463 & 8.75 & 0.32 & 0.050 \\
\hline \multirow[t]{3}{*}{$\pi(\mathrm{C} 8-\mathrm{C} 9)$} & 1.62058 & $\pi^{*}(\mathrm{C} 1-\mathrm{C} 7)$ & 0.13462 & 18.70 & 0.28 & 0.069 \\
\hline & & $\pi^{*}(\mathrm{C} 10-\mathrm{C} 11)$ & 0.32180 & 18.94 & 0.28 & 0.066 \\
\hline & & $\pi^{*}(\mathrm{C} 12-\mathrm{C} 13)$ & 0.28789 & 19.19 & 0.29 & 0.068 \\
\hline \multirow[t]{2}{*}{$\pi(\mathrm{C} 10-\mathrm{C} 11)$} & 1.64210 & $\pi^{*}(\mathrm{C} 8-\mathrm{C} 9)$ & 0.38463 & 22.31 & 0.28 & 0.071 \\
\hline & & $\pi^{*}(\mathrm{C} 12-\mathrm{C} 13)$ & 0.28789 & 18.31 & 0.29 & 0.066 \\
\hline \multirow[t]{2}{*}{$\pi(\mathrm{C} 12-\mathrm{C} 13)$} & 1.65857 & $\pi^{*}(\mathrm{C} 8-\mathrm{C} 9)$ & 0.38463 & 19.32 & 0.28 & 0.066 \\
\hline & & $\pi^{*}(\mathrm{C} 10-\mathrm{C} 11)$ & 0.32180 & 21.15 & 0.28 & 0.069 \\
\hline \multirow[t]{2}{*}{$\pi(\mathrm{N} 15-\mathrm{C} 16)$} & 1.79965 & $\pi^{*}(\mathrm{~N} 17-\mathrm{N} 18)$ & 0.00833 & 17.68 & 0.28 & 0.067 \\
\hline & & $\pi^{*}(\mathrm{C} 19-\mathrm{C} 24)$ & 0.37094 & 8.64 & 0.36 & 0.052 \\
\hline$\pi(\mathrm{N} 17-\mathrm{N} 18)$ & 1.85348 & $\pi^{*}(\mathrm{~N} 15-\mathrm{C} 16)$ & 0.39315 & 24.07 & 0.35 & 0.087 \\
\hline \multirow[t]{3}{*}{$\pi(\mathrm{C} 19-\mathrm{C} 24)$} & 1.63401 & $\pi^{*}(\mathrm{~N} 15-\mathrm{C} 16)$ & 0.39315 & 23.17 & 0.24 & 0.067 \\
\hline & & $\pi^{*}(\mathrm{C} 20-\mathrm{C} 21)$ & 0.30975 & 19.40 & 0.28 & 0.067 \\
\hline & & $\pi^{*}(\mathrm{C} 22-\mathrm{C} 23)$ & 0.33175 & 20.02 & 0.28 & 0.067 \\
\hline \multirow[t]{2}{*}{$\pi(\mathrm{C} 20-\mathrm{C} 21)$} & 1.66406 & $\pi^{*}(\mathrm{C} 19-\mathrm{C} 24)$ & 0.37094 & 19.70 & 0.29 & 0.067 \\
\hline & & $\pi^{*}(\mathrm{C} 22-\mathrm{C} 23)$ & 0.33175 & 20.72 & 0.28 & 0.068 \\
\hline$\pi^{*}(\mathrm{C} 2-03)$ & 0.25711 & $\pi^{*}(\mathrm{C} 1-\mathrm{C} 7)$ & 0.13462 & 67.78 & 0.02 & 0.069 \\
\hline$\pi^{*}(\mathrm{~N} 15-\mathrm{C} 16)$ & 0.02665 & $\pi^{*}(\mathrm{C} 19-\mathrm{C} 24)$ & 0.37094 & 52.47 & 0.05 & 0.070 \\
\hline$\pi^{*}(\mathrm{~N} 17-\mathrm{N} 18)$ & 0.46300 & $\pi^{*}(\mathrm{~N} 15-\mathrm{C} 16)$ & 0.39315 & 67.36 & 0.04 & 0.071 \\
\hline \multirow[t]{3}{*}{$\sigma(\mathrm{C} 1-\mathrm{C} 2)$} & 1.96787 & $\sigma^{*}(\mathrm{C} 1-\mathrm{C} 7)$ & 0.01952 & 3.66 & 1.31 & 0.062 \\
\hline & & $\sigma^{*}(04-\mathrm{C} 5)$ & 0.03286 & 3.41 & 0.93 & 0.050 \\
\hline & & $\sigma^{*}(\mathrm{C} 7-\mathrm{C} 8)$ & 0.02440 & 3.72 & 1.16 & 0.059 \\
\hline$\sigma(\mathrm{C} 1-\mathrm{C} 7)$ & 1.97658 & $\sigma^{*}(\mathrm{C} 7-\mathrm{C} 8)$ & 0.02440 & 3.35 & 1.25 & 0.058 \\
\hline$\sigma(\mathrm{C} 6-\mathrm{H} 27)$ & 1.98139 & $\sigma^{*}(04-\mathrm{C} 5)$ & 0.03286 & 4.27 & 0.75 & 0.051 \\
\hline$\sigma(\mathrm{C} 7-\mathrm{C} 8)$ & 1.97453 & $\sigma^{*}(\mathrm{C} 1-\mathrm{C} 7)$ & 0.01952 & 3.75 & 1.31 & 0.063 \\
\hline \multirow[t]{2}{*}{$\sigma(\mathrm{C} 7-\mathrm{H} 30)$} & 1.96478 & $\sigma^{*}(\mathrm{C} 1-\mathrm{N} 14)$ & 0.04307 & 9.74 & 0.88 & 0.083 \\
\hline & & $\sigma^{*}(\mathrm{C} 8-\mathrm{C} 13)$ & 0.02634 & 4.78 & 1.08 & 0.064 \\
\hline \multirow[t]{2}{*}{$\sigma(\mathrm{C} 12-\mathrm{C} 13)$} & 1.97881 & $\sigma^{*}(\mathrm{C} 7-\mathrm{C} 8)$ & 0.02440 & 3.87 & 1.19 & 0.061 \\
\hline & & $\sigma^{*}(\mathrm{C} 8-\mathrm{C} 13)$ & 0.02634 & 3.12 & 1.26 & 0.056 \\
\hline$\sigma(\mathrm{N} 14-\mathrm{N} 15)$ & 1.98460 & $\sigma^{*}(\mathrm{C} 16-\mathrm{C} 19)$ & 0.03063 & 4.66 & 1.38 & 0.072 \\
\hline \multirow[t]{2}{*}{$\sigma(\mathrm{N} 15-\mathrm{C} 16)$} & 1.98003 & $\sigma^{*}(\mathrm{C} 1-\mathrm{N} 14)$ & 0.04307 & 6.28 & 1.21 & 0.078 \\
\hline & & $\sigma^{*}(\mathrm{C} 16-\mathrm{C} 19)$ & 0.03063 & 2.15 & 1.33 & 0.048 \\
\hline \multirow[t]{2}{*}{$\sigma(\mathrm{N} 17-\mathrm{N} 18)$} & 1.97990 & $\sigma^{*}(\mathrm{C} 1-\mathrm{N} 14)$ & 0.04307 & 4.29 & 1.27 & 0.066 \\
\hline & & $\sigma^{*}(\mathrm{C} 16-\mathrm{C} 19)$ & 0.03063 & 3.66 & 1.39 & 0.064 \\
\hline
\end{tabular}




\begin{tabular}{|c|c|c|c|c|c|c|}
\hline \multirow[t]{2}{*}{$\sigma(\mathrm{C} 19-\mathrm{C} 24)$} & 1.97167 & $\sigma^{*}(\mathrm{C} 23-\mathrm{H} 39)$ & 0.01374 & 9.68 & 1.24 & 0.098 \\
\hline & & $\sigma^{*}(\mathrm{C} 24-\mathrm{H} 40)$ & 0.01351 & 20.70 & 6.23 & 0.322 \\
\hline \multirow[t]{2}{*}{$\mathrm{n} 2(03)$} & 1.84504 & $\sigma^{*}(\mathrm{C} 1-\mathrm{C} 2)$ & 0.07509 & 19.27 & 0.67 & 0.103 \\
\hline & & $\sigma^{*}(\mathrm{C} 2-04)$ & 0.09758 & 31.80 & 0.63 & 0.128 \\
\hline \multirow[t]{3}{*}{$\mathrm{n} 2(04)$} & 1.80299 & $\pi^{*}(\mathrm{C} 2-03)$ & 0.25711 & 45.32 & 0.34 & 0.112 \\
\hline & & $\sigma^{*}(\mathrm{C} 5-\mathrm{H} 25)$ & 0.01998 & 4.38 & 0.73 & 0.073 \\
\hline & & $\sigma^{*}(\mathrm{C} 5-\mathrm{H} 26)$ & 0.02004 & 4.39 & 0.73 & 0.073 \\
\hline \multirow[t]{2}{*}{$\mathrm{n} 1(\mathrm{~N} 14)$} & 1.48673 & $\pi^{*}(\mathrm{~N} 15-\mathrm{C} 16)$ & 0.39315 & 27.59 & 0.29 & 0.082 \\
\hline & & $\pi^{*}(\mathrm{~N} 17-\mathrm{N} 18)$ & 0.46300 & 48.54 & 0.25 & 0.099 \\
\hline \multirow[t]{2}{*}{$\mathrm{n} 1(\mathrm{~N} 15)$} & 1.93767 & $\sigma^{*}(\mathrm{~N} 14-\mathrm{N} 18)$ & 0.07213 & 8.13 & 0.81 & 0.072 \\
\hline & & $\sigma^{*}(\mathrm{C} 16-\mathrm{N} 17)$ & 0.04145 & 5.82 & 0.90 & 0.065 \\
\hline \multirow[t]{2}{*}{ n1(N17) } & 1.92946 & $\sigma^{*}(\mathrm{~N} 14-\mathrm{N} 18)$ & 0.46300 & 7.53 & 0.78 & 0.068 \\
\hline & & $\sigma^{*}(\mathrm{~N} 15-\mathrm{C} 16)$ & 0.02665 & 6.37 & 0.92 & 0.069 \\
\hline \multirow[t]{2}{*}{$\mathrm{n} 1(\mathrm{~N} 18)$} & 1.92946 & $\sigma^{*}(\mathrm{~N} 14-\mathrm{N} 15)$ & 0.04318 & 7.67 & 0.84 & 0.072 \\
\hline & & $\sigma^{*}(\mathrm{C} 16-\mathrm{N} 17)$ & 0.04145 & 5.55 & 0.93 & 0.064 \\
\hline
\end{tabular}

${ }^{a} \mathrm{E}(2)$ means energy of hyperconjucative interactions.

b Energy difference between donor and acceptor i and j NBO orbitals.

${ }^{c} \mathrm{~F}(\mathrm{i}, \mathrm{j})$ is the Fock matrix element between $\mathrm{i}$ and $\mathrm{j}$ NBO orbitals

The results of NBO analysis such as the occupation numbers with their energies for the interacting NBOs [interaction between natural bond orbital A and natural bond orbital B (A-B)] and the polarization coefficient amounts of atoms in title compound are presented using the B3LYP/6-311++G** level is summarized in Table 9 (Atoms labeling is according to Fig. 1). The size of polarization coefficients shows the importance of the two hybrids in the formation of the bond. The differences in electronegativity of the atoms involved in the bond formation are reflected in the larger differences in the polarization coefficients of the atoms ( $\mathrm{C}-\mathrm{O}, \mathrm{C}-\mathrm{N}$ and $\mathrm{C}-\mathrm{H}$ bonds). The calculated bonding orbital for the $\sigma(\mathrm{C} 1-\mathrm{C} 7)$ bond is the $\sigma=0.7110$ (sp1.38) + 0.7031 (sp1.64) with high occupancy 1.97658a.u. and low energy -0.78335 a.u.. The polarization coefficients of $\mathrm{C} 1=0.7110$ and $\mathrm{C} 7=$ 0.7031 shows low difference in polarization coefficients C1 and C7 atoms in C1-C7 bond and importance of two atoms in forming bond. Also in tetrazole ring, the calculated bonding orbital for the $\sigma(\mathrm{N} 17-\mathrm{N} 18)$ bond is $\sigma=0.7021(\mathrm{sp} 2.67)+0.7121(\mathrm{sp} 2.34)$ with low energy -0.91712 a.u. and high occupancy 1.97990 a.u.. The polarization coefficients of $\mathrm{N} 17=0.7021$ and $\mathrm{N} 18=0.7121$ shows low difference in polarization coefficients N17 and N18 atoms in N17-N18 bond and importance of two atoms in forming bond. The calculated bonding orbital for the $\pi(\mathrm{C} 2-03)$ bond of carbonyl group is $\pi=0.5330(\mathrm{sp} 1.00)+0.8332$ (sp99.99) with high energy -0.39782 a.u. and high occupancy 1.97806 a.u.. The polarization coefficients of $\mathrm{C} 2=0.5330$ and $03=0.8332$ shows large difference in polarization coefficients $\mathrm{C} 2$ and 03 atoms in $\mathrm{C} 2-03$ bond and importance of two atoms in forming bond and im-portance of $\mathrm{C} 2$ in forming $\pi(\mathrm{C} 2-03)$ bond compared with 03 atom. According to NBO analysis, the natural hybrid orbital n2(03) with occupancy 1.84504 a.u. and high energy -0.27623 
AliRamazani et al.

$\mathrm{P}$ a g e $\mid \mathbf{4 4}$

a.u. has p-character (99.91\%), while n1(03) occupy a lower energy orbital (-0.71114 a.u) with pcharacter (40.61\%) and high occupation number (1.97949 a.u). The natural hybrid orbital n2(04) has p-character (99.95\%), whereas $\mathrm{n} 1(04)$ has p-character (60.83\%). Also the natural hybrid orbital n1(N14) with low occupancy 1.48673 a.u. has p-character (99.98\%), whereas n1(N15), $\mathrm{n} 1(\mathrm{~N} 17)$ and $\mathrm{n} 1$ (N18) have p-character (59.56\%), (60.78\%) and (53.34\%). From Table 9, it is found that the pure p-type lone pair orbital participates the electron donation to $\sigma^{*}(\mathrm{C} 2-04)$ for $\mathrm{n} 2(\mathrm{O} 3) \rightarrow \sigma^{*}(\mathrm{C} 2-\mathrm{O} 4), \pi^{*}(\mathrm{C} 2-\mathrm{O} 3)$ for $\mathrm{n} 2(\mathrm{O} 4) \rightarrow \sigma^{*}(\mathrm{C} 2-\mathrm{O} 3)$ and $\sigma^{*}(\mathrm{~N} 17-\mathrm{N} 18)$ for $\mathrm{n} 1(\mathrm{~N} 14) \rightarrow \sigma^{*}(\mathrm{~N} 17-\mathrm{N} 18)$ interactions in the title compound.

Table 9. Calculated natural bond orbitals (NBO) and the polarization coefficient for each hybrid in selected bonds of the title compound using the B3LYP/6-311++G** level.

\begin{tabular}{|c|c|c|c|c|c|c|c|c|c|}
\hline $\begin{array}{l}\text { Occupa } \\
\text { ncy } \\
\text { (a.u.) }\end{array}$ & $\begin{array}{l}\text { Bond } \\
\text { (A-B)a }\end{array}$ & $\begin{array}{l}\text { Energy } \\
\text { (a.u.) }\end{array}$ & $\begin{array}{l}\text { EDA } \\
(\%)\end{array}$ & $\begin{array}{l}\text { EDB } \\
(\%)\end{array}$ & NBO & $\begin{array}{l}S(\%) \\
\text { (A) }\end{array}$ & $\begin{array}{l}S(\%) \\
\text { (B) }\end{array}$ & $\begin{array}{l}P(\%) \\
\text { (A) }\end{array}$ & $\begin{array}{l}P(\% \\
) \\
\text { (B) }\end{array}$ \\
\hline 1.96787 & $\sigma(\mathrm{C} 1-\mathrm{C} 2)$ & -0.69073 & 51.95 & 48.05 & $\begin{array}{l}0.7208(\mathrm{sp} 2.08)+ \\
0.6932(\mathrm{sp} 1.69)\end{array}$ & 32.43 & 37.22 & 67.52 & $\begin{array}{l}62.7 \\
4\end{array}$ \\
\hline 1.97658 & $\sigma(\mathrm{C} 1-\mathrm{C} 7)$ & -0.78335 & 50.56 & 49.44 & $\begin{array}{l}0.7110(\mathrm{sp} 1.38)+ \\
0.7031(\mathrm{sp} 1.64)\end{array}$ & 41.92 & 37.86 & 58.05 & $\begin{array}{l}62.0 \\
9\end{array}$ \\
\hline 1.85887 & $\begin{array}{l}\pi(\mathrm{C} 1- \\
\mathrm{C} 7)\end{array}$ & -0.30775 & 56.99 & 43.01 & $\begin{array}{l}0.7549(\mathrm{sp} 1.00)+ \\
0.6558(\mathrm{sp} 99.99)\end{array}$ & 0.01 & 0.03 & 99.96 & $\begin{array}{l}99.8 \\
9\end{array}$ \\
\hline 1.98345 & $\begin{array}{l}\sigma(\mathrm{C} 1- \\
\mathrm{N} 14)\end{array}$ & -0.83162 & 36.43 & 63.57 & $\begin{array}{l}0.6035(\mathrm{sp} 2.90)+ \\
0.7973(\mathrm{sp} 1.62)\end{array}$ & 25.61 & 38.17 & 74.28 & $\begin{array}{l}61.8 \\
0\end{array}$ \\
\hline 1.99437 & $\begin{array}{l}\sigma(\mathrm{C} 2- \\
03)\end{array}$ & -1.09925 & 35.39 & 64.61 & $\begin{array}{l}0.5949(\mathrm{sp} 1.90)+ \\
0.8038(\mathrm{sp} 1.46)\end{array}$ & 34.43 & 40.62 & 65.43 & $\begin{array}{l}59.2 \\
5 \\
\end{array}$ \\
\hline 1.97806 & $\begin{array}{l}\pi(\mathrm{C} 2- \\
03)\end{array}$ & -0.39782 & 30.58 & 69.42 & $\begin{array}{l}0.5330(\mathrm{sp} 1.00)+ \\
0.8332(\mathrm{sp} 99.99) \\
\end{array}$ & 0.01 & 0.01 & 99.51 & $\begin{array}{l}99.8 \\
7 \\
\end{array}$ \\
\hline 1.99114 & $\begin{array}{l}\sigma(\mathrm{C} 2- \\
04)\end{array}$ & -0.93373 & 31.54 & 68.46 & $\begin{array}{l}0.5616(\mathrm{sp} 2.53)+ \\
0.8274(\mathrm{sp} 2.10)\end{array}$ & 28.25 & 32.20 & 71.51 & $\begin{array}{l}67.7 \\
2\end{array}$ \\
\hline 1.98812 & $\begin{array}{l}\sigma(04- \\
\mathrm{C} 5)\end{array}$ & -0.82123 & 69.89 & 30.11 & $\begin{array}{l}0.8360(\mathrm{sp} 2.48)+ \\
0.5487(\mathrm{sp} 4.15)\end{array}$ & 28.68 & 19.36 & 71.27 & $\begin{array}{l}80.3 \\
5 \\
\end{array}$ \\
\hline 1.99032 & $\sigma(\mathrm{C} 5-\mathrm{C} 6)$ & -0.64480 & 50.61 & 49.39 & $\begin{array}{l}0.7114(\mathrm{sp} 2.22)+ \\
0.7028(\mathrm{sp} 2.47)\end{array}$ & 31.04 & 28.78 & 68.92 & $\begin{array}{l}71.1 \\
7\end{array}$ \\
\hline 1.97453 & $\sigma(\mathrm{C} 7-\mathrm{C} 8)$ & -0.69227 & 49.60 & 50.40 & $\begin{array}{l}0.7043(\mathrm{sp} 1.78)+ \\
0.7099(\mathrm{sp} 2.15) \\
\end{array}$ & 35.93 & 31.78 & 64.04 & $\begin{array}{l}68.1 \\
8 \\
\end{array}$ \\
\hline 1.97318 & $\sigma(\mathrm{C} 8-\mathrm{C} 9)$ & -0.70692 & 51.34 & 48.66 & $\begin{array}{l}0.7165 \text { (sp1.98) + } \\
0.6976(\mathrm{sp} 1.82)\end{array}$ & 33.51 & 35.44 & 66.45 & $\begin{array}{l}64.5 \\
2 \\
\end{array}$ \\
\hline 1.97905 & $\begin{array}{l}\sigma(\mathrm{C} 9- \\
\mathrm{C} 10)\end{array}$ & -0.72033 & 50.24 & 49.76 & $\begin{array}{l}0.7088(\mathrm{sp} 1.76)+ \\
0.7054(\mathrm{sp} 1.80)\end{array}$ & 36.23 & 35.70 & 63.73 & $\begin{array}{l}64.2 \\
5 \\
\end{array}$ \\
\hline 1.98460 & $\begin{array}{l}\sigma(\mathrm{N} 14- \\
\mathrm{N} 15)\end{array}$ & -0.90989 & 54.99 & 45.01 & $\begin{array}{l}0.7416(\mathrm{sp} 2.22)+ \\
0.6709(\mathrm{sp} 3.29)\end{array}$ & 31.00 & 23.29 & 68.92 & $\begin{array}{l}76.5 \\
5\end{array}$ \\
\hline 1.99036 & $\begin{array}{l}\sigma(\mathrm{N} 14- \\
\mathrm{N} 18)\end{array}$ & -0.91240 & 55.68 & 44.32 & $\begin{array}{l}0.7462(\mathrm{sp} 2.24)+ \\
0.6657(\mathrm{sp} 3.23) \\
\end{array}$ & 30.80 & 23.62 & 69.12 & $\begin{array}{l}76.2 \\
2 \\
\end{array}$ \\
\hline 1.98003 & $\begin{array}{l}\sigma(\mathrm{N} 15- \\
\mathrm{C} 16)\end{array}$ & -0.85709 & 59.19 & 40.81 & $\begin{array}{l}0.7694(\mathrm{sp} 1.75)+ \\
0.6388(\mathrm{sp} 2.27) \\
\end{array}$ & 36.36 & 30.56 & 63.54 & $\begin{array}{l}69.3 \\
3 \\
\end{array}$ \\
\hline
\end{tabular}




\begin{tabular}{|c|c|c|c|c|c|c|c|c|c|}
\hline 1.79965 & $\begin{array}{l}\pi(\mathrm{N} 15- \\
\mathrm{C} 16)\end{array}$ & -0.33092 & 58.42 & 41.58 & $\begin{array}{l}0.7643(\mathrm{sp} 1.00)+ \\
0.6448(\mathrm{sp} 1.00)\end{array}$ & 0.00 & 0.00 & 99.81 & $\begin{array}{l}99.8 \\
1 \\
\end{array}$ \\
\hline 1.98581 & $\begin{array}{l}\sigma(\mathrm{C} 16- \\
\mathrm{N} 17)\end{array}$ & -0.81974 & 41.94 & 58.06 & $\begin{array}{l}0.6476(\mathrm{sp} 2.31)+ \\
0.7619(\mathrm{sp} 1.97)\end{array}$ & 30.18 & 33.63 & 69.73 & $\begin{array}{l}66.2 \\
7\end{array}$ \\
\hline 1.97370 & $\begin{array}{l}\sigma(\mathrm{C} 16- \\
\mathrm{C} 19)\end{array}$ & -0.68157 & 50.28 & 49.72 & $\begin{array}{l}0.7091(\mathrm{sp} 1.55)+ \\
0.7051(\mathrm{sp} 2.28)\end{array}$ & 39.24 & 30.51 & 60.74 & $\begin{array}{l}69.4 \\
4\end{array}$ \\
\hline 1.97990 & $\begin{array}{l}\sigma(\mathrm{N} 17- \\
\mathrm{N} 18)\end{array}$ & -0.91712 & 49.30 & 50.70 & $\begin{array}{l}0.7021(\mathrm{sp} 2.67)+ \\
0.7121(\mathrm{sp} 2.34)\end{array}$ & 27.24 & 29.90 & 72.60 & $\begin{array}{l}69.9 \\
4\end{array}$ \\
\hline 1.85348 & $\begin{array}{l}\pi(\mathrm{N} 17- \\
\mathrm{N} 18)\end{array}$ & -0.36134 & 52.03 & 47.97 & $\begin{array}{l}0.7213 \text { (sp1.00) + } \\
0.6926 \text { (sp99.99) }\end{array}$ & 0.00 & 0.01 & 99.73 & $\begin{array}{l}99.7 \\
1\end{array}$ \\
\hline 1.98562 & $\begin{array}{l}\sigma(\mathrm{C} 5- \\
\mathrm{H} 25)\end{array}$ & -0.52819 & 59.74 & 40.26 & $\begin{array}{l}0.7729(\mathrm{sp} 3.00)+ \\
0.6345(\mathrm{~s})\end{array}$ & 24.96 & 99.96 & 74.96 & 0.04 \\
\hline 1.98579 & $\begin{array}{l}\sigma(\mathrm{C} 5- \\
\mathrm{H} 26) \\
\end{array}$ & -0.52836 & 59.70 & 40.30 & $\begin{array}{l}0.7727(\mathrm{sp} 3.01)+ \\
0.6345(\mathrm{~s})\end{array}$ & 24.94 & 99.96 & 74.98 & 0.04 \\
\hline 1.97949 & $\mathrm{n} 1(03)$ & -0.71114 & - & - & sp0.68 & 59.37 & - & 40.61 & - \\
\hline 1.84504 & $\mathrm{n} 2(03)$ & -0.27623 & - & - & sp1.00 & 0.01 & - & 99.91 & - \\
\hline 1.96449 & $\mathrm{n} 1(04)$ & -0.58652 & - & - & sp1.55 & 39.14 & - & 60.83 & - \\
\hline 1.80299 & $\mathrm{n} 2(04)$ & -0.34082 & - & - & sp1.00 & 0.00 & - & 99.95 & - \\
\hline 1.48673 & $\mathrm{n} 1(\mathrm{~N} 14)$ & -0.30186 & - & - & sp1.00 & 0.00 & - & 99.98 & - \\
\hline 1.93767 & $\mathrm{n} 1(\mathrm{~N} 15)$ & -0.43991 & - & - & sp1.48 & 40.37 & - & 59.56 & - \\
\hline 1.92946 & $\mathrm{n} 1(\mathrm{~N} 17)$ & -0.41105 & - & - & sp1.55 & 39.15 & - & 60.78 & - \\
\hline 1.95188 & $\mathrm{n} 1(\mathrm{~N} 18)$ & -0.46342 & - & - & sp1.14 & 46.61 & - & 53.34 & - \\
\hline
\end{tabular}

a A-B is the bond between atom A and atom B. (A: natural bond orbital and the polarization coefficient of atom; A-B: natural bond orbital and the polarization coefficient of atom B).

\section{Conclusion}

In the present study, the electronic structure of ethyl-(Z)-3-phenyl-2-(5-phenyl-2H-1,2,3,4tetraazol-2-yl)-2-propenoate has been analyzed using the HF and DFT calculations (HF/6-311++G** and B3LYP/6-311++G** levels). From the theoretical and experimental geometric parameters values, it can be seen experimental values are in good agreement with the theoretical values. According to results of $1 \mathrm{H}$ and $13 \mathrm{C}$ NMR chemical shifts, it can be seen a good agreement between experimental and calculated values. The natural charge (NBO) analysis of the title compound shows that the highest positive charge is observed for $\mathrm{C} 2$ atom due to attachment to 03 and 04 atoms and their electron-withdrawing nature, therefore it is more acidic. The FMO analysis suggests that charge transfer is taking place within the molecule. From the MEP map, it can be seen negative region of the title compound is mainly focused on 03 atom, phenyl and tetrazole rings, therefore they suitable site for electrophilic attack. According to the results of NBO analysis, the $\pi^{*} \rightarrow \pi^{*}$ transitions have the highest resonance energies compared with other interactions of the title compound such as C2-03 $\rightarrow$ C1-C7, N15-C16 $\rightarrow$ C19-C24 and N17-N18 $\rightarrow$ N15-C16 that lead to stability of the title compound. 


\section{References}

[1] Schmidt B., Schieffcr B., J. Med. Chem., 2003, 46:2261

[2] Bekhit A.A., El-Sayed O.A., Aboulmagd E., Park J.Y. Eur. J. Med. Chem., 2004, 39:249

[3] Rajasekaran A., Thampi P.P. Eur J. Med. Chem., 2004, 39:273

[4] Park H., Merz K.M. J. Med. Chem., 2005, 48:1630

[5] Moderhack D.J. Prakt Chem. /Chem-Ztg, 1998, 340:687

[6] Singh H., Chala A.S., Kapoor V.K., Paul D., Malhotra R.K. Prog. Med. Chem., 1980, 17:151

[7] Shahab S., Filippovich L., Sheikhi M., Yahyaei H., Aharodnikova M., Kumar R., Khaleghian M. Am. J. Mater. Synth. Process., 2017, 5:17

[8] Shahab S., Filippovich L., Sheikhi M., Kumar R., Dikusar E., Yahyaei H., Muravsky A. J. Mol. Struct., 2017, 1141:703

[9] Shoaei S.M., Kazemizadeh A.R., Ramazani A. Chin. J. Struct. Chem., 2011, 30:568

[10] Abu-Eittah R.H., El-Kelany K. E.A. Mol. Biomol. Spectrosc., 2012, 99:316

[11] Alam M., Alam M.J., Nami S.A.A., Khan M.S., Ahmad S., Lee D.U. J. Mol. Struct., 2015, 1099:588

[12] Mahmood A., Khan I.U. , Longo R.L., Irfan A., Shahzad S.A. Comp. Rend. Chim., 2015, 18:422

[13] Ramazani A., Kazemizadeh A.R., Ahmadi E., Noshiranzadeh N., Souldozi A. Curr. Org. Chem., 2008, 12:59

[14] Ramazani A., Abbasi Motejadded A., Ahmadi E. Phosphorus Sulfur Silicon Relat. Elem., 2006, 181:233

[15] Ramazani A., Kazemizadeh A.R., Ahmadi E., Ślepokura K., Lis T.Z. Naturforsch., 2006, 61b:1128

[16] Ramazani A., Rahimifard M., Noshiranzadeh N., Souldozi A. Phosphorus Sulfur Silicon Relat. Elem., 2007, 182:413

[17] Ramazani A., Ahmadi Y., Zeinali Nasrabadi F., Rouhani M. J. Heterocyclic. Chem., 2013, 50:1294

[18] Ramazani A., Souldozi A. Phosphorus Sulfur Silicon Relat. Elem., 2009, 184:2344

[19] Ramazani A., Rezaei A., Ahmadi Y. Phosphorus, Sulfur Silicon Relat. Elem., 2012, 187:22

[20] Ramazani A., Zeinali Nasrabadi F., Ślepokura K., Lis T., Joo S.W.J. Heterocycl Chemi., 2015, 54:55 [21] Becke A.D. J. Chem. Phys., 1993, 98:5648

[22] Frisch M.J., Trucks G.W., Schlegel H.B., Scuseria G.E., Robb M.A., Cheeseman J.R., Scalmani G. , Barone, B. Mennucci, G. A. Petersson, H. Nakatsuji, M. Caricato, X. Li, H. P. Hratchian, A.F. Izmaylov, J. Bloino V., Zheng G., Sonnenberg J.L., Hada M., Ehara M., Toyota K., Fukuda R., Hasegawa J., Ishida M., Nakajima T., Honda Y., Kitao O., Nakai H., Vreven T., Montgomery J.A., Peralta J.E., Ogliaro F., Bearpark M., Heyd J.J., Brothers E., Kudin K.N., Staroverov V.N., Kobayashi R., Normand J., Raghavachari K., Rendell A., Burant J.C., Iyengar S.S., Tomasi J., Cossi M., Rega N., Millam J.M., Klene 
M., Knox J.E., Cross J.B., Bakken V., Adamo C., Jaramillo J., Gomperts R., Stratmann R.E., Yazyev O., Austin A.J., Cammi R., Pomelli C., Ochterski J.W., Martin R.L., Morokuma K., Zakrzewski V.G., Voth G.A., Salvador P., Dannenberg J.J., Dapprich S., Daniels A.D., Farkas Ö., Foresman J.B., Ortiz J.V., Cioslowski J., Fox D.J. Gaussian09, Revision A.02, Gaussian Inc., Wallingford, CT, 2009.

[23] Sheikhi M., Sheikh D., Ramazani A. S. Afr. J. Chem., 2014, 67:151

[24] Frisch A., Nielson A.B., Holder A.J.,GAUSSVIEW User Manual, Gaussian Inc., Pittsburgh, PA, 2000.

[25] Yahyaei H., Kazemizadeh A.R., Ramazani A. Chinese J. Struct. Chem., 2012, 31:1346

[26] Shahab S., Sheikhi M., Filippovich L., Dikusar Anatol'evich E., Yahyaei H. J. Mol. Struct., 2017, 1137:335

[27] Joshi B.D., Tandon P., Jain S. The Himalayan Phys., 2012, 3:44

[28] Habibi D., Faraji A.R., Sheikh D., Sheikhi M., Abedi S. RSC. Adv., 2014, 4:47625

[29] Shiri L., Sheikh D., Faraji A.R., Sheikhi M., Seyed Katouli S.A. Lett. Org. Chem., 2014, 11:18

[30] Sheikhi M., Sheikh D. Rev. Roum. Chim., 2014, 59:761

[31] Vipin Das K.G., Yohannan Panicker C., Narayana B., Nayak P.S., Sarojini B.K., Al-Saadi A.A. Mol. Biomol. Spectrosc., 2015, 135:162

[32] Fukui K. Science., 1982, 218:747

[33] Ramazani A., Rouhani A., Mirhadi E., Sheikhi M., Ślepokura K., Lis T. Nano. Chem. Res., 2016, 1:87

[34] Weinhold F., Landis C.R., Natural Bond Orbitals and Extensions of Localized, 2001.

[35] Shahab S., Sheikhi M., Filippovich L., Kumar R., Dikusar E., Yahyaei H., Khaleghian M. J. Mol. Struct., 2017, 1148:134

How to cite this manuscript: Ali Ramazani*, Masoome Sheikhi, Hooriye Yahyaei. Molecular Structure, NMR, FMO, MEP and NBO Analysis of Ethyl-(Z)-3-phenyl-2-(5-phenyl-2H-1,2,3,4tetraazol-2-yl)-2-propenoate Based on HF and DFT Calculations. Chemical Methodologies 1(1), 2017, 28-48. DOI: 10.22631/chemm.2017.95510.1006. 